\title{
Antioxidative and therapeutic effects of spirulina on trichloroethylene induced cutaneous irritation balb/c mice
}

\author{
Gurbuz N${ }^{1}$, Coskun $\mathrm{ZK}^{2}$, Omeroglu $\mathrm{S}^{3}$, Bayraktar AC, Ciraci Z4 \\ Laboratory Animal Breeding and Experimental Research Centre, Faculty of Medicine, Gazi University, \\ Ankara, Turkey.neslihan.gurbuz@gazi.edu.tr
}

\begin{abstract}
Objectives: To evaluate the antioxidative and therapeutic effects of spirulina on the trichloroethylene induced cutaneous irritation balb/c mice.

Background: During recent years, an attention has been focused on the antioxidant potential of Spirulina species. Methods: Balb/c mice were randomized into the four groups. At the end of the each application, the rats were sacrificed and dorsal skin was taken. Histopathologic and immunohistochemical evaluations were conducted, oxidative stress was assessed by the measurement of malondialdehyde (MDA) levels, superoxide dismutase (SOD) activities and nitric oxide (NO) production.

Results: There was a statistically significant decreased disruption in epidermal integrity, oedema in intercellular dermis, disorganization in collagen fibres and immunoreactivity in the pre acute dermatitis/ antioxidant and the post acute dermatitis/ treatment groups when compared to the acute dermatitis group $(p<0.05)$.

Conclusion: The results of the present study indicate the antioxidative and therapeutic effects of Spirulina on trichloroethylene induced cutaneous irritation balb/c mice (Tab. 2, Fig. 8, Ref. 33). Full Text in PDF www.elis.sk. Key words: spirulina, trichlorethylene, acute dermatitis, antioxidative effect, treatment effect, balb/c mice.
\end{abstract}

Spirulina is a blue-green alga that is rich in proteins, vitamins, essential amino acids, minerals and essential fatty acids. It is produced commercially and sold as a food supplement in health food stores all over the world. Until very recently, the interest in Spirulina was mainly for its nutritive value. Over the past few years, however, it has been found to have many additional pharmacological properties (1-5). Many preclinical studies and a few clinical studies suggested several therapeutic effects ranging from a reduction of cholesterol and cancer to the enhancement of the immune system. Spirulina is effective for treating certain allergies, anemia, cancer, hepatotoxicity, viral and cardiovascular diseases, hyperglycemia, hyperlipidemia, immunodeficiency and inflammatory processes, among others (6). During recent years, an attention has been focused on the antioxidant potential of Spirulina species. It has been found that Spirulina is capable of inhibiting carcinogenesis and organ-specific toxicity due to its antioxidant properties $(5,7-9)$.

${ }^{1}$ Laboratory Animal Breeding and Experimental Research Centre, Faculty of Medicine, Gazi University, Ankara, Turkey, ${ }^{2}$ Department of Anatomy, Faculty of Medicine Gazi University, Ankara, Turkey, ${ }^{3}$ Department of Histology and Embryology, Faculty of Medicine, Gazi University, Ankara, Turkey, and ${ }^{4}$ Department of Biochemistry, Faculty of Medicine, Gazi University, Ankara, Turkey

Address for correspondence: N. Gurbuz, PhD, Medical Faculty of Gazi University, Laboratory Animal Breeding and Experimental Research Centre, Ankara, Turkey.

Phone: +90.312 .2024709$

Acknowledgements: This research was financially supported by the Research Fund of the Gazi University BAP (Grant : 01/2010-19).
Trichloroethylene (TCE), a colourless and volatile organic solvent, is widely used in industry as metal degreasing and dry cleaning agent for various cleaning operations, such as computer chips and electronic product, and has been a major chemical hazard during occupational exposure. Under current technological and economical conditions, a direct skin contact with TCE often occurs and is inevitable during the process of various operations $(10,11)$.

TCE has been shown to produce a broad spectrum of toxicological effects in the skin. With the development of industry, an increasing number of reports on skin injuries have been implicated with TCE in recent years. TCE-caused dermatitis by occupational exposure has become a new and urgent problem to be solved in the field of public health in fast-developing countries (12-14).

The effect of TCE on skin irritation has received little attention. The irritation effects of TCE on skin have been examined a few study (15).

Our aim was to investigate antioxidative and therapeutic effects of Spirulina on trichloroethylene induced cutaneous irritation $\mathrm{balb} / \mathrm{c}$ mice.

\section{Material methods}

Animals

Eight to ten-week-old female BALB/c mice rats, weighing 20 g each, were obtained from Gazi University Laboratory Animal Breeding and Experimental Research Centre (Ankara, Turkey).

They were held in stainless-steel cages in the animal room, which was maintained on a $12 \mathrm{~h}$ light/ $12 \mathrm{~h}$ dark cycle at $21-22^{\circ} \mathrm{C}$. All rats were allowed free access to food and water and libitum. The 
structure of the study and animal experimental procedures were approved by the Ethical Committee of Gazi University.

\section{Chemicals}

All agents including TCE (99.5\% purity, analytical grade or the highest commercial grade available) were purchased from Sigma Chemical Co. (St. Louis, MO, USA). Concentration of TCE used in this study were: $80 \%$ (v/v dissolved in olive oil).

\section{Induction of acute irritation}

In order to enhance the adherence, the dorsal skin of the animals about $2.5 \mathrm{~cm}^{2}$ size area were de-lipidized with ethanol-wetted cotton pads. After air-drying, $50 \mu \mathrm{l}$ of TCE dissolved in olive oil was painted topically on the delipidized site, and then covered with sterile plastic film, which was fixed with non-irritant adhesive tape. The film was removed $4 \mathrm{~h}$ post-application (as an occupational hazard, $4 \mathrm{~h}$ of application represent a maximum continuous exposure in a working session at a workplace) and the treated area was gently wiped with normal solution to remove any residual liquid from the skin surface. One hour later, skin reactions were observed visually. This treatment was given twice daily (at $3 \mathrm{~h}$ interval) for 1 day in an acute irritation, respectively (15).

\section{Experimental design}

$20 \mathrm{balb} / \mathrm{c}$ mice randomized into the four groups

Group 1 (acute dermatitis group $n=5$ ): TCE group ( $80 \%$ ). At the end TCE of treatment, the animals were killed and the dorsal skin was examined.

Group 2 (pre acute dermatitis/antioxidant group $\mathrm{n}=5$ ): 0.06gr spirulina was administered orally via gavage 7 days before the acute dermatitis test ( $80 \% \mathrm{TCE})$. At the end TCE of treatment, the animals were killed and the dorsal skin was examined.

Group 3 (post acute dermatitis/ treatment group $n=5$ ): 0.06 g spirulina was administered orally via gavage 7 days after the acute dermatitis test ( $80 \%$ TCE). Eight days after the TCE treatment, the animals were killed and the dorsal skin was measured.

Group 4 (control group $n=5$ ): no application was done. At the end of the eight day, the animals were killed and the dorsal skin was measured.

\section{LPO activities measurement}

The levels of MDA, served as an indicator of LPO, was determined in the tissues directly by the reverse phase high-pressure liquid chromatography method (HPLC) after derivatisation with 2,4- dinirophenylhidrazine (Türközkan et al, 2006) (16).

\section{Sample preparation for total MDA in HPLC}

\section{Tissue preparation}

$500 \mathrm{mg}$ tissue was homogenized by Vetra-Turrax in a volume of $1.15 \% \mathrm{KCl}, 24000 \mathrm{rpm} / \mathrm{min}(17)$. For an alkaline hydrolysis of protein bound MDA, $200 \mu \mathrm{L} 6 \mathrm{M} \mathrm{NaOH}$ was added to $1 \mathrm{ml}$ homogenenate in an eppendorf cup and the sample was incubated in a $600 \mathrm{C}$ water bath for $45 \mathrm{~min}$. An aliquot of $1 \mathrm{ml}$ was diluted with an equal volume of acetonitrile to precipate proteins. The resulting suspension was then vortex mixed for $30 \mathrm{~s}$ and centrifuged at $15000 \mathrm{~g}$ for $10 \mathrm{~min}$. The upper clear supernatant $(0.25 \mathrm{ml})$ was transferred to a $2 \mathrm{ml}$ eppendorf cup, mixed with $25 \mu \mathrm{L}$ DNPH solution ( $5 \mathrm{mM}$ in $2 \mathrm{M} \mathrm{HCl}, \mathrm{pH}=0.09$ ) and incubated for $10 \mathrm{~min}$ at room temperature. After derivatisation, the samples were filtered through a $0.2 \mu \mathrm{m}$ filter. Aliquots of $20 \mu \mathrm{L}$ were injected into HPLC system $(18,17,19,20-21)$.

\section{Preparation of the standard curve}

MDA standard was prepared by dissolving $25 \mu \mathrm{L} 1,1,3,3$ tetraethoxypropane (TEP) in $100 \mathrm{ml}$ of water to give a $1 \mathrm{mM}$ stock solution. Working standard was prepared by hydrolysis of $1 \mathrm{ml}$ TEP stock solution in $50 \mathrm{ml} 1 \%$ sulfuric acid and incubation for $2 \mathrm{~h}$ at room temperature. The resulting MDA standard of $20 \mathrm{nmol} /$ $\mathrm{ml}$ was further diluted with $1 \%$ sulfuric acid to yield the final concentration of $10.5,2.5,1.25$ and $0.625 \mathrm{nmol} / \mathrm{ml}$ to get the standard curve for the estimation of total MDA (19). $0.250 \mathrm{ml}$ of standards were mixed with $25 \mu \mathrm{L}$ DNPH solution and incubated for $10 \mathrm{~min}$. A $20 \mu \mathrm{L}$ volume of the reaction mixture was directly injected onto HPLC system by filtered through a $0.2 \mu \mathrm{m}$ filter or unfiltered (18).

\section{HPLC analysis}

The samples were analyzed on an Agilent HP 1100 series HPLC apparatus (USA). The analytical column ODS 2 C18 (5 $\mu \mathrm{m}$ particle size, $125 \mu 4 \mathrm{~mm}$ ). In our experiment, analytical column was $5 \mu \mathrm{m}$ pore size spherisorb ODS-2 C18 reserve phase column $(125 \mu 4 \mathrm{~mm})$ the retention time of the MDAhydra zone averaged 6.0 min for daily runs. The mobile phase was acetonitrile-distilled water (38: 62, v/v) containing $0.2 \%(\mathrm{v} / \mathrm{v})$ acetic acid. HPLC apparatus was isocratic a condition at a flow rate $1 \mathrm{ml} / \mathrm{min}$ and $\mathrm{UV}$ detector was set at $310 \mathrm{~nm}$. MDA peaks were determined according to its retention time and confirmed by spiking with added exogenous standard. Concentrations of MDA were calculated from the standard curve prepared from 1,1,3,3 tetraethoxypropane and expressed as $\mathrm{nmol} / \mathrm{ml}$ for the plasma and $\mathrm{nmol} / \mathrm{mg}$ for the tissues $(22,18)$.

\section{Determination of SOD production}

The anti-oxidative enzyme-SOD activities was determined according to the method of Nishigori et al (1989) (23), which is based on inhibition of nitroblue tetrazolium (NBT) reduction by the xanthine oxidase system as a superoxide generator. $50 \mu \mathrm{l}$ of the homogenate supernatant was added in the reaction mixture containing $985 \mu \mathrm{l}$ of $100 \mathrm{mM}$ PBS (pH 7.4), $0.3 \mathrm{mM} \mathrm{K} 2 \mathrm{H} 2$-EDTA, 0.5 $\mathrm{mM}$ NBT, and $0.1 \mathrm{mM}$ xanthine. The mixture was preincubated for $3 \mathrm{~min}$ at $25{ }^{\circ} \mathrm{C}$. Then, $10 \_1$ of $0.02 \mathrm{U} / \mathrm{ml}$ xanthine oxidase was added and centrifuged. Absorbance was recorded at $550 \mathrm{~nm}$.

SOD activities was calibrated from the standard curve of percentage inhibition of NBT reduction and expressed as units/mg protein. One unit of SOD was defined as the amount causing $50 \%$ inhibition in the NBT reduction rate. The results were expressed as $\mathrm{U} / \mathrm{mg}$ protein.

\section{Determination of $\mathrm{NO}$ production}

Since NO rapidly degrades to nitrate and nitrite in aqueous solution, the total nitrate and nitrite levels were estimated as an 
Tab. 1. Antioxidant and Therapeutics effect of Spirulina on TCE induced acute irritation on skin of balb/c mice.

\begin{tabular}{|c|c|c|c|c|}
\hline & $\begin{array}{c}\text { Acute } \\
\text { dermatitis } \\
\text { group }(n=5)\end{array}$ & $\begin{array}{c}\text { Pre acute } \\
\text { dermatitis/antioxidant } \\
\text { group }(n=5)\end{array}$ & $\begin{array}{c}\text { Post acute } \\
\text { dermatitis/treatment } \\
\text { group }(n=5)\end{array}$ & $\begin{array}{c}\text { control } \\
\text { group }(n=5)\end{array}$ \\
\hline MDA (nmol/g tissue) & $13,22 \pm 6,73$ & $4,31 \pm 2,57 *$ & $3,91 \pm 2,50 *$ & $6,40 \pm 5,20 *$ \\
\hline $\mathrm{NO}(\mu \mathrm{mol} / \mathrm{mg}$ protein $)$ & $37,50 \pm 25,44$ & $33,34 \pm 28,60$ & $18,68 \pm 11,00$ & $21,50 \pm 8,30$ \\
\hline SOD (U/mg protein) & $7,23 \pm 1,50$ & $8,22 \pm 1,32 * *$ & $11,01 \pm 2,73^{*}$ & $8,00 \pm 2,00$ \\
\hline
\end{tabular}

Data are presented as mean $\pm \mathrm{SD},{ }^{*} \mathrm{p}<0.05$ compared with acute dermatitis group, ${ }^{* *} \mathrm{p}<0.05$ compared with post acute dermatitis/ treatment group

Tab. 2. The evaluation of Masson trikrom staining and Caspase- 9 with immunohistochemical staining.

\begin{tabular}{lccc}
\hline & $\begin{array}{c}\text { Disruption in epidermal } \\
\text { integrity }\end{array}$ & $\begin{array}{c}\text { Intracellular oedema } \\
\text { in dermis }\end{array}$ & $\begin{array}{c}\text { Disorganization in } \\
\text { collagen fibres }\end{array}$ \\
\hline Acute dermatitis group & +++ & +++ & ++ \\
Post acute dermatitis/treatment group & - & + & + \\
Pre acute dermatitis/antioxidant group & - & + & + \\
\hline
\end{tabular}

index of NO production. This test used a spectrophotometric method based on the Griess reaction (Green et al, 1982) (24). To measure nitrite plus nitrate levels, $0.1 \mathrm{ml}$ supernatant was mixed with Griess reagent (consisting of one part $1 \%$ sulfanilamide in 5 $\%$ orthophosphoric acid) at room temperature for $10 \mathrm{~min}$, and the absorbance was then measured at $550 \mathrm{~nm}$. The concentration of nitrite plus nitrate was calculated according to a $\mathrm{NaNO}_{2}$ standard linear curve. Results were expressed as $\mu \mathrm{mol} / \mathrm{mg}$ protein.

\section{Histopathological analysis}

Masson Trichrome staining

Skin samples taken from control, acute dermatitis, pre acute dermatitis/antioxidant, post acute dermatitis/ treatment groups were determined in $10 \%$ formaline solution for $72 \mathrm{~h}$.

Cross-sections of 4-5 $\mu \mathrm{m}$ taken from tissues under routine histological treatments were dyed with Masson Trichrome. (Masson trichromica Goldner, Bioptica 011802). The preparations were observed under Leica DM 4000 B microscope. Observations were evaluated as: Disruption in epidermal integrity, oedema in intercellular dermis, disorganization in collagen fibres $(-:$ not observed, + : minimum level, ++ : medium level, +++ maximum) (Tab. 2).

\section{Immunohistochemical method}

Skin samples from each group were dyed immunohistochemically with [Caspase 9] LAP 6 Ab-4 (Thermo Scientific)] in order to determine apoptosis.

Immunoreactivity in each group was evaluated as (no retention: - , medium level retention: + , maximum level retention: ++ ) (Tab. 2).

\section{Statistical analysis}

Throughout the text, data were expressed as the mean \pm standard deviation (S.D.). All statistical analysis were performed by the Mann-Whitney U test.

Antioxidant and therapeutics effects were investigated through the levels of skin MDA, SOD, NO.

Table 1 demonstrate the levels of skin MDA, SOD, NO levels in acute dermatitis, pre acute dermatitis/antioxidant and post acute dermatitis/ treatment groups.

We have observed a significant increase in MDA level at the end of the TCA application (acute dermatitis group) when compared to the control group $(\mathrm{p}<0.05)$.

MDA levels were decreased in the pre acute dermatitis/ antioxidant and the post acute dermatitis/treatment group when compared to the acute dermatitis groups $(\mathrm{p}<0.05)$.

No significant differences in skin MDA levels in the pre acute dermatitis/antioxidant group when compared to the post acute dermatitis/ treatment group $(\mathrm{p}>0.05)$.

We have observed no significant differences in skin SOD levels in the acute dermatitis group when compared to the control group ( $p>0.05)$ However, SOD level was decreased in the acute dermatitis group.

We have observed a significant increase in the skin SOD level in the post acute dermatitis/treatment group when compared to the acute dermatitis group $(\mathrm{p}<0.05)$. There was a significant difference in the skin SOD level in the pre acute dermatitis/antioxidant group and the post acute dermatitis/treatment group $(\mathrm{p}<0.05)$. The skin SOD level was higher in the post acute dermatitis/treatment group than in the pre acute dermatitis/ antioxidant group $(\mathrm{p}<0.05)$.

No significant differences in the skin NO levels in the pre acute dermatitis/antioxidant and post acute dermatitis/treatment group when compared to the acute dermatitis and control group $(\mathrm{p}>0.05)$. However, NO level was increased in the acute dermatitis group.

We have observed a significant increase in the epidermal integrity disruption, oedema in intercellular dermis, disorganization in collagen fibres and immunoreactivity after TCA application in the acute dermatitis group compared to the post acute dermatitis/ treatment and the pre acute dermatitis/antioxidant groups $(\mathrm{p}<0.05)$.

Epidermal integrity disruption, oedema in intracellular dermis, disorganization in collagen fibres, immunreactivity were decreased in the post acute dermatitis/treatment group and the pre acute dermatitis/ antioxidant group.

No significant differences in the epidermal integrity disruption, oedema in intercellular dermis, disorganization in collagen fibres, immunoreactivity in the post acute dermatitis/treatment group when compared to the pre acute dermatitis/antioxidant group ( $\mathrm{p}>0.05)$.

After staining with masson-trichrome at the tissue sections; disruption in the epidermal integrity, separation of dermis and epidermis, disorganization in the collagen fibres in dermis layers 


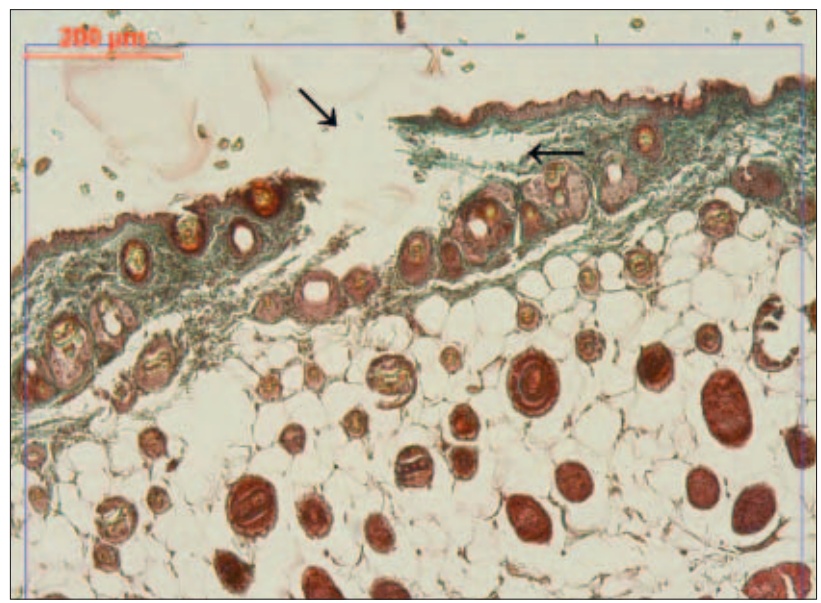

Fig. 1. Acute dermatitis group; epidermal integrity disruption $(\downarrow)$, separation of epidermis-dermis layers (masson-trichrome, $x \mathbf{1 0}$ ).

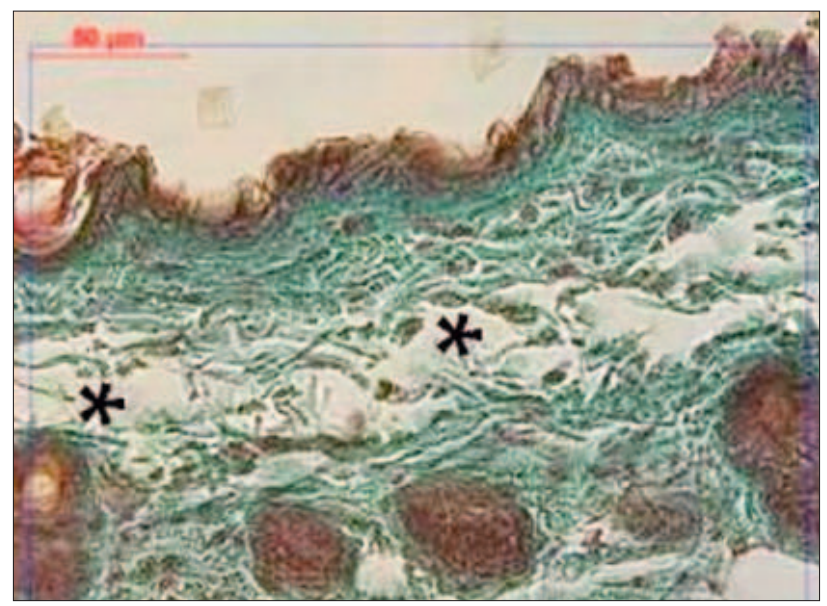

Fig. 2. Acute dermatitis group; Disorganization in the collagen fibres in dermis and large spaces filled with oedema $(*)$ (masson-trichrome, $x 40$ ).
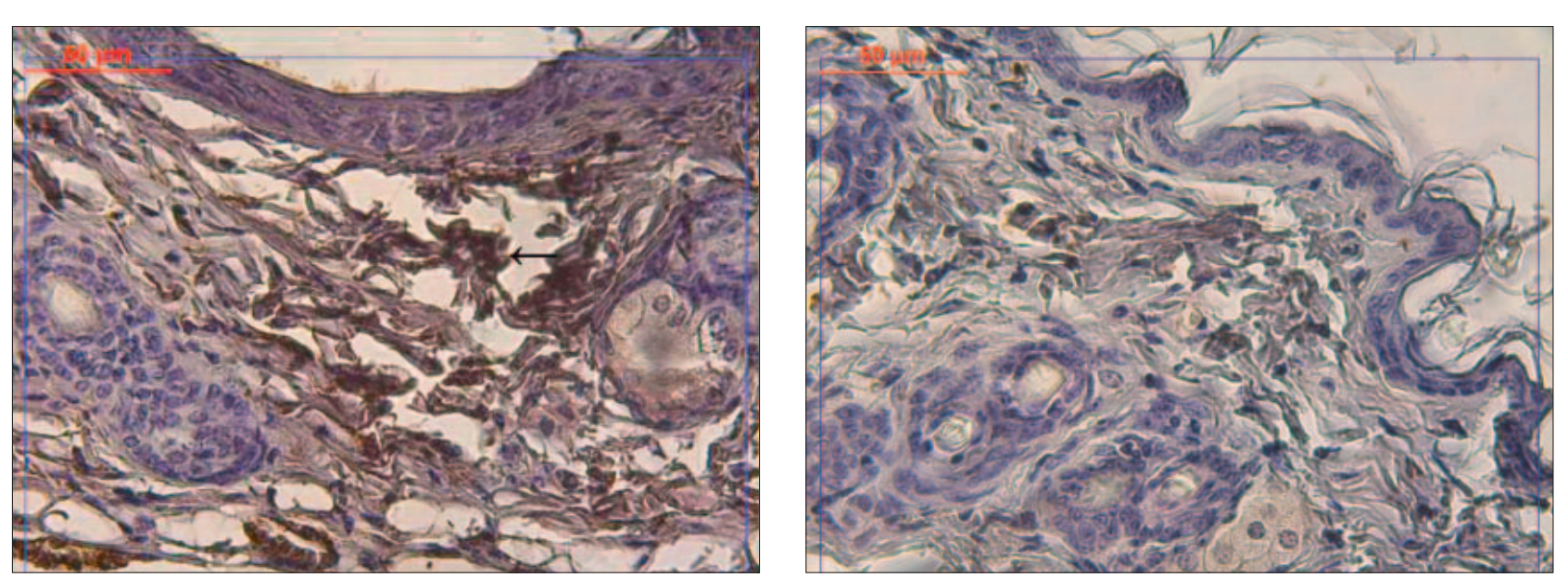

Figs 5 and 6. Acute dermatitis group; Smaller frame: immunoreactivity in epidermal layers and dermis. Immunoreactivity of collagen fibres can be observed better in the larger frame. (Caspase-9, x 10, x 40).

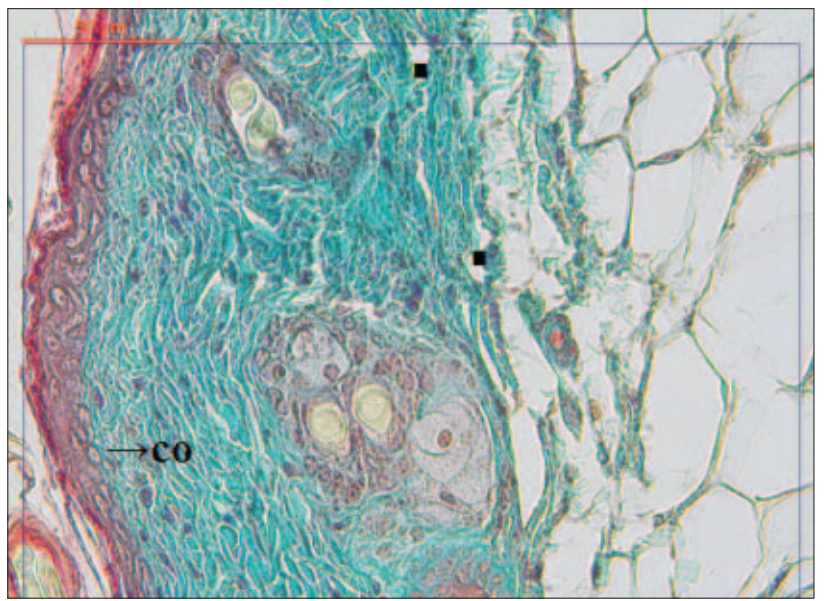

Fig. 3. Post acut dermatitis/ treatment group; collagen fibres in dermis (co) and minimal spaces filled with oedema (-) (masson-trichrome, $x 40$ ).

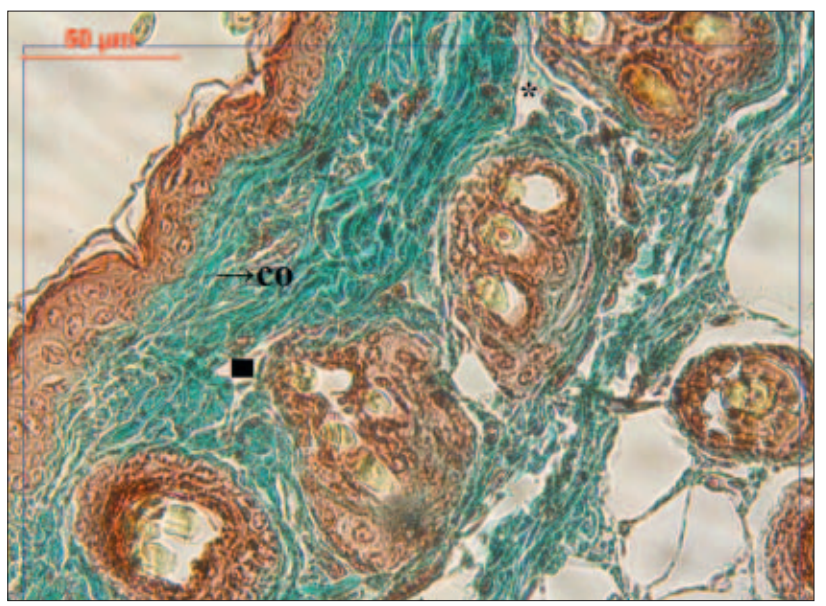

Fig. 4. Pre acute dermatitis antioxidant group; collagen fibres in dermis (co) and spaces filled with oedema $\left({ }^{*}\right)$ (masson-trichrome, $x$ 40). 

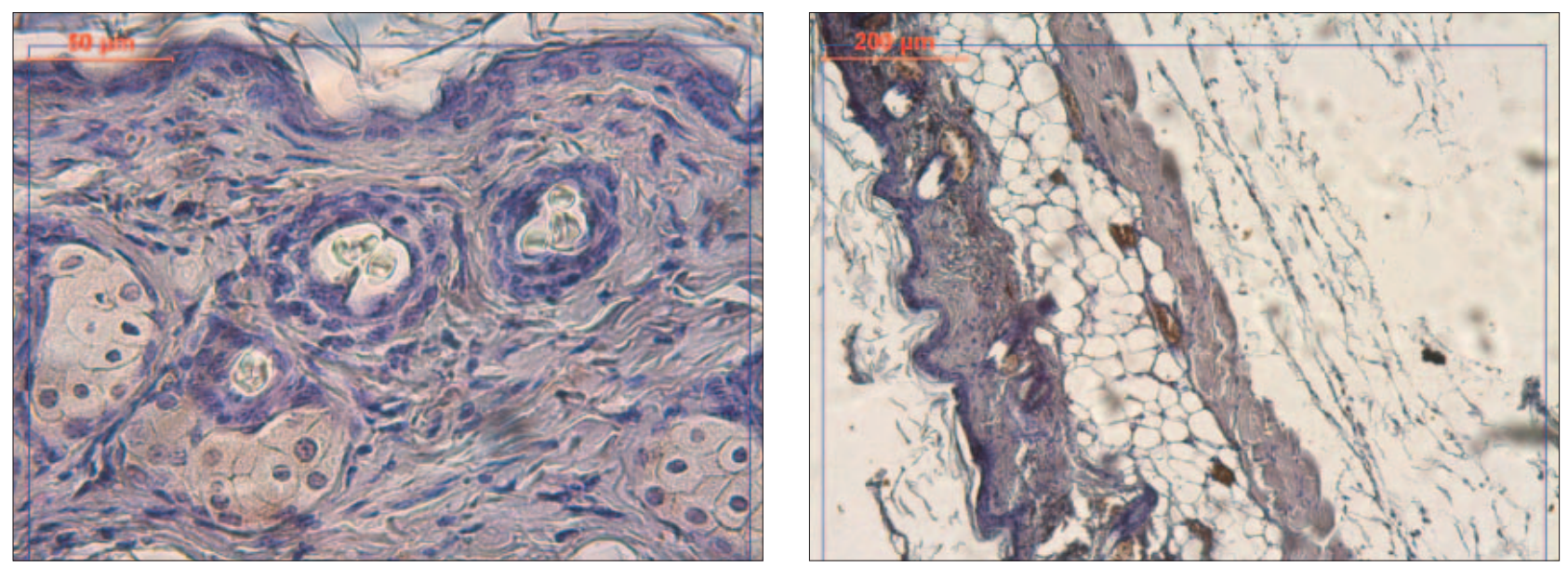

Figs 7 and 8. As a result, after immunohistochemical staining with Caspase-9, increase in immunoreactivity showed that acute dermatitis increased apoptosis in the epidermal and dermal layers. Immunoreactivity decreased in post acute dermatitis/treatment vs pre acute dermatitis/ antioxidant groups.

were observed. Large spaces filled with oedema were detected between the collagen fibres (Figs 1,2).

On the other hand, in the post acute dermatitis/treatment group and the pre acute dermatitis/antioxidant groups, it was observed that epidermal integrity was preserved and epidermis-dermis contact continued after staining with masson-trichrome. Moreover, there were minimal spaces of oedema compared to acute dermatitis group and collagen fibres were found to be more organized (Figs 3,4).

Caspase-9 immunohistological staining revealed that immunoreactivity was increased in epidermal cells and collagen fibres in the acute dermatitis group compared to the other groups (Figs 5,6 ). On the other hand, immunoreactivity was found to be decreased in the epidermal cells and dermal collagen (Tab. 1) in the post acute dermatitis/treatment group and pre acute dermatitis/ antioxidant groups (Figs 7, 8).

\section{Discussion}

TCE induced skin irritation - respond to drug - have proven useful in skin cutaneous irritation in balb/c hairless mice (25).

In the acute and cumulative TCE irritation, the skin developed erythema and oedema, and the predominant histopathological features were hyperkeratosis, spongiosis and inflammatory cell infiltrates. In parallel to these morphological changes, an acute TCE irritation also concentration-dependently increased MDA levels and inhibited SOD activities of the skin (15).

Thus, the model is rather suitable for the assessment of the effect of TCE induced cutaneous irritation (15) of balb/c mice. Therefore, we used TCE induced acute irritation and assessment of the effects of potential agents on the dorsal skin of balb/c mice.

In our study, we successfully induced an acute irritation on balb/c mice with TCE. In the skin, disintegrity in the epidermis, intracellular oedema in the dermis, disorganization in collagen fibres and increased immunoreactivity were observed.

TCE-caused dermatitis via occupational exposure has become a new and urgent problem to be solved in the field of public health in fast-developing countries (15). Skin irritation is defined as a non-immunological, local inflammatory reaction, which is usually reversible and is characterized by erythema and oedema, following a single or repeated application of a chemical to the same cutaneous site (26).

Shen $\mathrm{T}$ et al have shown that skin irritation was induced by TCE as histologically examined by microscopy and oxidative stress assessed by measurement of malondialdehyde (MDA) levels, superoxide dismutase (SOD) activities and nitric oxide (NO) production. Under an acute and cumulative TCE irritation, the skin developed erythema and oedema, and the predominant histopathological features were hyperkeratosis, spongiosis and inflammatory cell infiltrates (15).

The results of our study have shown that a light microscopic evaluation revealed a decrease in disintegrity in the epidermis, intracellular oedema in the dermis, disorganization in collagen fibres. Moreover, immunohistochemical evaluation revealed a decreased immunoreactivity in the post acute dermatitis/ treatment group and the pre acute dermatitis/antioxidant groups.

This shows the activity of spirulina TCE induced acute irritation on balb/c mice.

This is the first study to demonstrate the antioxidative and therapeutic effects of spirulina on trichloroethylene induced cutaneous irritation in balb/c mice.

In literature, we can find Wang et al (25) trial of different substances. Wang et al (25) have also shown that changes of nitric oxide after trichloroethylene irritation in hairless mice skin and a protection of ginkgo biloba extract (GbE) and vitamin $\mathrm{E}(\mathrm{VE})$. TCE can produce the irritation on the dorsal skin of BALB/c hairless mice and induce the significant increase of the NO levels. GbE and VE can protect the skin from TCE irritation damage.

LPO has been considered a major presentation of oxidative stress and the results from the oxidation of membrane-associated polyunsaturated fatty acids of phospholipids. The increased membrane LPO is considered to evoke immune and inflammatory responses. MDA has been extensively utilized as the biomarker of 
LPO. An increased formation and subsequent accumulation of MDA have been found in various pathological conditions including skin disease $(27,28)$.

In the present study, dorsal skin MDA levels were found to be significantly decreased in the pre acute dermatitis/ antioxidant and the post acute dermatitis/treatment group when compared to the acute dermatitis groups $(\mathrm{p}<0.05)$, indicating that spirulina is effective against lipid peroxidation.

Shen $\mathrm{T}$ et al (15) have also shown that TCE exposure led to an increase in MDA levels in a concentration-dependent manner in acute irritation.

Lee IC et al (29) have shown a protective effects of pine bark extract (PBE) against hexavalent chromium [Cr(VI)]-induced dermatotoxicity in rats. Skin reactions were evaluated by histopathological changes and oxidative stress parameters. Histopathological examination showed moderate to severe necrosis and desquamation in the epidermis and inflammation and haemorrhage in the dermis. In addition, an increased malondialdehyde (MDA) concentration of the skin were observed in the $\mathrm{Cr}(\mathrm{VI})$ group. PBE treatment reduced MDA concentrations. PBE has a protective effect against $\mathrm{Cr}(\mathrm{VI})$-induced dermatotoxicity and is useful as a protective agent against various dermal lesions induced by oxidative stress.

SOD is an endogenous enzymatic scavenger and constitutes the first line of defense against oxygen-derived free radicals, converting the superoxide anion $\left(\mathrm{O}_{2}^{-{ }^{-}}\right)$into $\mathrm{H} 2 \mathrm{O} 2(27,28)$.

Our study, no significant differences were found in skin SOD levels in the acute dermatitis group when compared to the control group ( $p>0.05$ ) However, SOD level was decreased in the acute dermatitis group.

In literature, Shen T et al (15) have demonstrated that an acute TCE irritation inhibited SOD activities of the skin hairless mice.

TCE induced a reduction of SOD activities. TCE induced reduction of SOD activities was mirrored by an increase of LPO in an acute irritation. This parallel reduction in SOD activities could represent a significant enzyme depletion due to clearance of the free radicals inside the skin and thus indicated a high degree of free radical production and LPO occurrence. The anti-oxidative capacity was apparently damaged in the skin by TCE treatment, which would exacerbate toxic effects due to LPO (15).

There were significant differences in skin SOD level in the pre acute dermatitis/antioxidant group and the post acute dermatitis/ treatment group $(p<0.05)$. Skin SOD level was higher in the post acute dermatitis/ treatment group than in the pre acute dermatitis/ antioxidant group $(\mathrm{p}<0.05)$.

In the literature review, we did not find any increase or decrease of SOD with an administered agent in balb/c mice TCE induced skin irritation. In our study, spirulina has an enhanced therapeutic effect in the post acute dermatitis/treatment group.

In our study, NO level was increased in the acute dermatitis group when compared to the control group but there was no significant difference $(p>0.05)$. Skin N0 levels were reduced in the pre acute dermatitis/antioxidant group and the post acute dermatitis/treatment group but the decrease was not significant $(\mathrm{p}>0.05)$.
Wang L et al (25) have shown that TCE can produce the irritation on the dorsal skin of BALB/c hairless mice and have also shown that in the protection group $(1 \% \mathrm{GbE}, 10 \% \mathrm{GbE}, 10 \%$ VE and $20 \% \mathrm{VE}$ ), the NO level were reduced, with the statistically significant differences $(\mathrm{p}<0.05)$.

The increase in TCE-evoked NO production may serve as a mediator and contribute to the development of erythema and inflammation, as well as be responsible for nonspecific immune defense mechanisms in TCE induced skin injuries. These findings not only provide an experimental evidence that TCE is capable of increasing oxidative stress by cutaneous irritation, but also support their hypothesis that an increased oxidative stress may play an important role in the pathogenesis of TCE-induced skin irritation (15).

Several lines of evidence indicate that TCE could generate free radicals and induce oxidative stress increase in other tissue, such as liver, lung and also lead to hepatitis and lung lesion $(30,31,32$, 33). Shen T et al (15) study's have shown the hypothesis that TCE exerts an effect on skin via oxidative stress mediated mechanism, which was tested in hairless balb/c mice with histopathologic evaluation. We also tested this hypothesis that exerts an effect on skin tissue via oxidative stress mediated mechanism in balb/c mice with histopathologic and immunohistochemical evaluations. An increased oxidative stress, histopathologic and immunohistochemical effects was decreased by a protective agent spirulina.

To our knowledge, this is the first report of the antioxidative and therapeutic effects of spirulina on the trichloroethylene induced cutaneous irritation $\mathrm{balb} / \mathrm{c}$ mice

In conclusion, the present study indicates the efficacy of spirulina on the trichloroethylene induced cutaneous irritation balb/c mice.

We think that this effect of spirulina is due to its antioxidative (15) and therapeutic (25) properties.

\section{References}

1. Belay A, Ota Y, Miyakawa K, Shimamatsu H. Current Knowledge on Potential Health Benefits of Spirulina. J Appl Phycol 1993; 5: 235-241.

2. Bilinkova LP, Gorobets OB, Baturo AP. Biological Activity of Spirulina. Zh Epidemiol 2001; 2: 114-118.

3. Khan Z, Bhadouria P, Bisen PS. Nutrional and Therapeutic Potential of Spirulina. Curr Pharm Biotechnol 2005; 6: 373-379.

4. Mohan IK, Khan M, Shobha JC. Protection Against Cisplatin- Induced Nephrotoxicity by Spirulina in Rats. Cancer Chemother Pharmacol 2006; 58: 802-808.

5. Kuhad A, Tirkey N, Pilkhwal S, Chopra K. Renoprotective Effect of Spirulina Fusiformis on Cisplatin-Induced Oxidative Stress and Dysfunction in Rats. Ren Fail 2006a; 28: 247-254

6. Chamorro G, Salazar M, Araujo KG, dos Santos Cp, Ceballos G, Castillo LF. Update on Pharmacology of Spirulina (Arthrospira), an Unconventional Food. Arch Lationam Nutr 2002; 52: 232-240.

7. Upasani CD, Balaraman R. Protective Effecet of Spirulina on Lead Induced Deterious Changes in the Lipid Peroxidation and Endogeneous Antioxidants in Rats. Phytother Res 2003; 17: 330-334.

8. Kuhad A, Tirkey N, Pilkhwal S, Chopra K. Effects of Spirulina, a Blue Green Algae, on Gentamycin-Induced Oxidative Stres and Renal Dysfunction in Rats. Fundam Clin Pharmacol 2006b; 20: 121-128. 
9. Lu HK, Hsieh CC, Hsu JJ, Yang YK, Chou HN. Preventive Effects of Spirulina Platensis on Skeletel muscle Damage under Exercise-Induced Oxidative Stres. Eur J Appl Physiol 2006b; 98: 220-226.

10. Agency for Toxic Substances and Disease Registry, Division of Toxicology, 1995. Toxicolgical Profile for Trichloroethylene. Update Draft for Public Comments. ATSDR, Atlanta GA.

11. IARC, 1995. Dry Cleaning some Chlorinated Solvents and other Industrial Chemicals IARC Monographs on the Evaluation of Carcinogenic to Humans vol.63, Lyon, 33-221.

12. Huang HI, Li L, Chen B, Huang JX, Kuang SR. New Problems Caused by Occupational Trichloroethylene Exposure. Int J Immunopathol Pharmacol 2002; 15: 30-32.

13. Nakajima T, Yamanoshita O, Kamijima M, Kishi R, Ichihara G. Genaralized Skin Reactions in Relation to Trichloroethylene Exposure: A Review from the Viewpoint of Drug-Metabolizing Enzymes. J Occup Health 2003; 45: 8-14.

14. Chiu WA, Caldwell JC, Keshava N, Scoot CS. Key Scientific Issues in the Health Risk Assessment of Trichloroethylene. Environ Health Perspect 2006; 114: 1445-1449.

15. Shen T, Zhu QX, Yang $S$ et al. Trichloroethylene Induced Cutaneous Irritation Balb/c Hairless mice: Histopathological Changes and Oxidative Damage. Toxicology 2008; 248 (2-3): 113-120.

16. Türközkan N, Erdamar H, Seven I. Measurement of Total Malondialdehyde in Plasma and Tissues by High- Performance Liguid Chromatography and Thiobarbituric Acid Assay Firat Tip Dergisi 2006; 11(2): 88-92.

17. Ceconi C, Cargnoni A, Pasini E, Condorelli E, Curello S, Ferrari R. Evaluation of phospholipid peroxidation as malondialdehyde during myocardial ischemia and reperfusion injury. Am J Physiol 1991; 260: H1057-1061.

18. Pilz J, Meineke I, Gleiter CH. Measurement of free and bound malondialdehyde in plasma by high-performance liquid chromatography as the 2,4-dinitrophenylhydrazine derivative. J Chromatogr B Biomed Sci Appl 2000; 742: 315-25.

19. Verbunt RJ, Egas JM, Van der Laarse A. Risk of overestimation of free malondialdehyde in perfused rat hearts due to homogenization artifacts. Cardiovasc Res 1996; 31: 603-606.

20. Stevens RG, Morris JE, Cordis GA, Anderson LE, Rosenberg DW, Sasser LB. Oxidative damage in colon and mammary tissue of the HFEknockout mouse. Free Radic Biol Med 2003; 34: 1212-1216.

21. Cini M, Moretti A. Studies on lipid peroxidation and protein oxidation in the aging brain. Neurobiol Aging 1995; 16: 53-57.
22. Cordis GA, Das DK, Riedel W. High-performance liquid chromatographic peak identification of 2, 4-dinitrophenylhydrazine derivatives of lipid peroxidation aldehydes by photodiode array detection. J Chromatogr A 1998; 798: 117-123.

23. Nishigori C, Miyashi Y, Inamura I, Takebe H. Reduced Superoxide Dismutase Activities in Xeroderma Pigmentosum Fibroblasts. J Invest Dermatol 1989; 93: 506-510.

24. Green LC, Wagner DA, Glogowski J, Skipper PL, Wishnok JS, Tannenbaum SR. Analysis of Nitrata, Nitrite, and in Biological Fluids. Anal Biochem 1982; 126: 131-138.

25. Wang L, Shen T, Zhou CF, Yu JF, Zhu QX. Changes of nitric oxide after trichloroethylene irritation in hairless mice skin and protection of ginkgo biloba extract and vitamin E. Zhonghua Lao Dong Wei Sheng Zhi Ye Bing Za Zhi.2009; 27 (4): 207-210.

26. Chew AL, Maibach HI. Occupational issues of irritant contact dermatitis. Int Arch Occup Environ Health 2003; 76: 339-346.

27. Briganti, S., Picardo, M. Antioxidant activities, lipid peroxidation and skin diseases. What's new? J Eur Acad Dermatol Venereol 2003; 17 : 663-669.

28. Sezer E, Ozugurlu F, Ozyurt H, Sahin S, Etikan I. Lipid peroxidation and antioxidant status in lichen planus. Clin Exp Dermatol 2007; 32: $430-434$.

29. Lee IC, Kim SH, Shin IS, et al. Protective Effects of Pine Bark Extract on Hexavalent Chromium-Induced Dermatotoxicity in Rats. Phytother Res 2012 Feb 17. doi: 10.1002/ptr.4610. [Epub ahead of print]

30. Channel SR, Latendresse JR, Kidney JK et al. A subchronic exposure to trichloroethylene causes lipid peroxidation and hepatocellular proliferation in male B6C3F1 mouse liver. Toxicol Sci 1998; 43: 145-154.

31. Mark T, John C, David D, et al. Oxidative stress and DNA damage in Fisher rats following acute exposure to trichloroethylene or perchloroethylene. Toxicology 1999; 138: 43-53.

32. Griffin JM, Blossom SJ, Jackson SK, et al. Trichloroethylene accelerates an autoimmune response by Th1 T cell activation in MRL $+/+$ mice. Immunopharmacology 2000; 46: 123-137.

33. Chen SJ, Wang JL, Chen JH, Huang RN. Possible involvement of glutathione and p53 in trichloroethylene- and perchloroethylene-induced lipid peroxidation and apoptosis in human lung cancer cells. Free Radic Biol Med 2002; 33: 464-472.

Received May 29, 2012. Accepted January 20, 2013. 